\title{
Article \\ Optimization of the Aesthetic Design of an Agronomic Product Inspired by an Asymmetric Shape of Water
}

\author{
Dolores Parras-Burgos * (D), Daniel G. Fernández-Pacheco (D) and Francisco J. F. Cañavate \\ Department of Structures, Construction and Graphic Expression, Universidad Politécnica de Cartagena, \\ 30202 Cartagena, Spain; daniel.garcia@upct.es (D.G.F.-P.); francisco.canavate@upct.es (F.J.F.C.) \\ * Correspondence: dolores.parras@upct.es; Tel.: +34-868-07-11-84
}

Citation: Parras-Burgos, D.;

Fernández-Pacheco, D.G.; Cañavate,

FJ.F. Optimization of the Aesthetic

Design of an Agronomic Product Inspired by an Asymmetric Shape of Water. Symmetry 2021, 13, 561.

https://doi.org/10.3390/sym13040561

Academic Editor: José Ignacio Rojas Sola

Received: 9 March 2021

Accepted: 26 March 2021

Published: 29 March 2021

Publisher's Note: MDPI stays neutral with regard to jurisdictional claims in published maps and institutional affiliations.

Copyright: (c) 2021 by the authors. Licensee MDPI, Basel, Switzerland. This article is an open access article distributed under the terms and conditions of the Creative Commons Attribution (CC BY) license (https:// creativecommons.org/licenses/by/ $4.0 /)$.

\begin{abstract}
Industrial products have been highlighted in the agronomic field more for their technical and functional aspects than for their visual aesthetics. Currently, this concept has changed and has favoured the development of innovative products taking into account all the factors involved in the conception of a product. This article describes a real industrial product redesign case that was functionally innovative and a reference in the agronomic domain. Due to the large number of copies that emerged from its competitors, this design required a new image in its aesthetic appearance to differentiate it from the rest. The difficulty of this project lay in the technical limitations to develop it, so a conceptual design process based on analogies and inspired by nature was necessary to find the most appropriate shape. Based on this methodology, a symmetrical and static design was transformed into one with asymmetrical and dynamic shapes inspired by the helicoidal movement of water. This new design gave this product an innovative, symbolic, and differentiating image that allowed its industrial registration in a large number of countries.
\end{abstract}

Keywords: design process; creativity; innovation; product design; bioinspiration

\section{Introduction}

When conceiving products, it is not enough to simply overcome functional (the function they perform) and operational (how they work) problems, but to also harmonise them with aspects related to shape, technology, aesthetics, psychology, anatomy, physiology, ergonomics, etc., [1,2]. So apart from fulfilling its function, a product must transmit its meaning and communicate it through its shape, colours, textures, and materials, etc., [3,4]. The visual appearance of products is, therefore, a key factor as to how consumers perceive and evaluate a product's properties since vision provides more data much more quickly [5].

Product design is no isolated activity. It forms part of a company's overall strategy in which the purpose of each new product being developed must be questioned. Indeed, the company must mobilise all its technical, human, and financial resources to conceive a project before it can move on to the development and production stages [3]. In this sense, companies that value design at a higher level obtain a greater degree of innovation [6,7], and technology companies that emphasize aesthetic design obtain greater advantages [8-14] and impact on the market [15-17].

Inspiration has long since been associated with creative professions, like music, art, science, engineering, architecture, and industrial design [18-20]. Industrial design is closely linked to the process of shaping products' visual appearance. Creativity can be defined as the level of product distinction among its competitors [21], highlighting the relevance of design [22], as well as the management of the process to obtain more innovative products [23]. Designing creative products is a company's achievement which may provide it with a competitive advantage. This competitive advantage will lead to better market results obtained with the new product, which will allow the sale targets, growth, profits, and profitability initially set out by the company to be met [24]. In industry, creativity is 
not necessarily the equivalent to a company's success but, without it, long-term failure can be certainly considered, as some studies indicate $[25,26]$.

Designers' purpose is to define the visual appearance of the new products by seeking inspiration from a wide variety of sources [11,18,27]. Although it is not known which resources can be more effective [28], it is clear that support systems for the creative process are necessary $[29,30]$. It can be stated that a product may be successful not only if it possesses better aesthetic quality and intelligent functionality, but also if it satisfies customers through the emotions that they feel while using it. Bioinspired designs may offer a more emotional relationship with users with varying degrees of responsiveness [31]. Some studies show the great potential of nature as a source of inspiration [32,33], being a relevant model in other disciplines with a socioeconomic impact on the present and future [34].

If nature is used as a reference to obtain shapes, then the different morphologies contained in nature must be contemplated, which all follow constantly repeated patterns and are always governed by the various forces controlling nature. All these shapes will bring about different responses in products depending on how they are applied and what the project objective is [35]. As perception psychology states, it is precisely because of this shape aspect being reasoned or not that an object can be recognised as an item based on something natural. Moreover, if it is a shape reasoned on something natural, it will give way to something that can be called "bionic aesthetics" [36].

The systematic study of nature is an essential task to create new alternatives for systems, mechanisms, structures, etc. Understanding natural principles-spirals, flows, behaviours, shapes, orders-represents the richest source of knowledge for design projects, and for a qualitative vision of the structures we create [36,37]. If nature is observed in a general way, it can be seen to contain an endless number of shapes that change according to circumstances. However, if it is observed in more detail, we can conclude that a certain number of shapes and patterns exist that are repeated and contemplate a series of physical properties or limitations. Nature contains a vast quantity of shapes and textures that can act as a source of inspiration to obtain aesthetically appealing, functional, and exciting designs [38].

Some studies have recognized that analogy-based design is an effective method for developing creativity and generating novel ideas [39,40]. By definition, biologicallyinspired design involves cross-domain analogies and has, in practice, led many new innovative designs to be accomplished. Therefore, the biological inspiration design is an ideal domain in which to study creative analogies [41]. Analogical reasoning is a method to identify connections or similarities between different elements, being a relevant cognitive tool to solve design problems [42]. In this sense, successful examples of the application of aesthetic designs inspired by nature can be found in the literature, from the design of furniture and interior equipment performed by students in technical universities [43] to the design of solar panels using fractal shapes in a professional company [44].

In the agronomic field, the products that are marketed, on most occasions, have stood out more for functional and technical aspects than for aesthetic aspects, a characteristic that has not been given excessive importance. One of the main problems that arise when dealing with aesthetic design projects in this type of products is the limitations that exist due to the technical specifications required, in terms of materials, dimensions, connectivity with other components, etc., making it difficult to innovate in this type of product's aesthetic appearance. On the other hand, although aesthetics is not a determining factor for the purchase of certain agronomic products, it is a representation of a company's brand image. The agronomic sector is very competitive at a global level, so offering a differentiating image that represents values of quality and innovation in certain products is key to positioning oneself as a reference in the market. This article describes the real case of a product that underwent different transformations in its design over the years, from a functional point of view in the early years to changes in its aesthetic design in later years, in order to position and maintain itself as a reference product in the market.

The main contributions of this paper are summarized as follows: 
- Description of the process of redesigning the visual appearance of a real agronomic product by transforming its symmetrical and static shapes into asymmetrical and dynamic shapes.

- Use of nature as a source of inspiration for shapes and movements in the conceptual design phase as a key factor in the innovation of a product's image.

- Example of how to highlight the importance of aesthetic design in industrial products as a factor that enhances the brand image of companies and differentiates them from their competitors.

\section{The Product's Background}

From a reductionist perspective, a company can be one whose main mission is to manufacture products and consumer goods [3]. However, a company can be much more than that: it is a human group that undertakes projects and performs actions that affect its surroundings and social, material, cultural and economic domains [45]. A company is also a complex functional system made up of interconnected elements that outwardly projects its influence [46]. The case described herein was developed by a company that was created in the 1980s in South East Spain, which is one of the aridest areas in Europe. Thus, water scarcity has marked its business vision until the present-day to promote "the Water Culture" by emphasising the water and environmental resources around us.

Within the range of products marketed by this company, the present study focuses on the filter case. This component is part of a modular range interconnected with other products, emphasising two elements that are located inside: the disc filter element and the helix device. A disc filtering element is a device that allows the filtering media inside filters to be percolated and cleaned. It comprises a filtering medium composed of a stack of grooved discs, a functional support structure, and an auxiliary element known as a "clogging-retardant device". The helix (the clogging-retardant device) is the system's key element, which resulted from carefully studying a water-efficient design. Located at the bottom of the cartridge, it possesses some baffle plates which, at a suitable angle of tilt, generate a helicoidal centrifuge effect that moves away from a high percentage of the particles suspended in water from the discs. This makes maintenance tasks less frequent, not so intense, and it also saves water.

Metal filters were commercialized until 1998. This type of filter was formed by a metal case with the following configuration: (i) a metal base whose interior held the disc filtering element; (ii) an upper lid made of thermoplastic material; and (iii) a stainless-steel clamp to join the two parts (Figure 1).

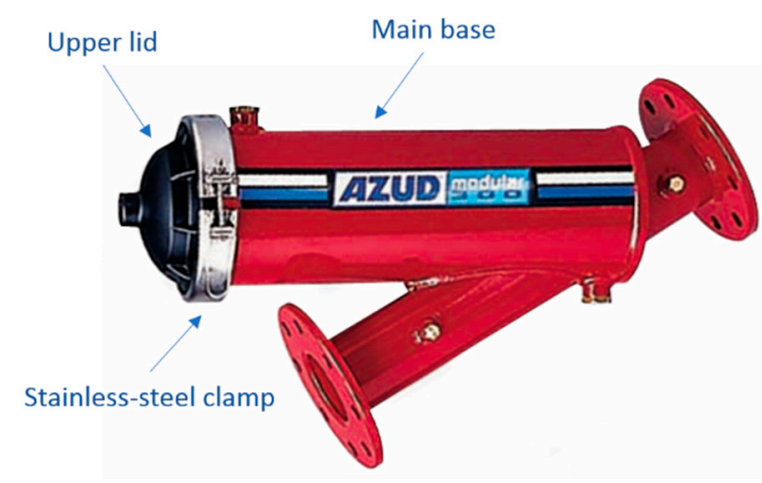

Figure 1. The Modular 300 metal filter.

However, in 1998 the company launched a new filter range called Classic and manufactured in thermoplastic to remove $90 \%$ of metal filters. This opportunity also permitted to solve some technical and functional problems, as for instance:

- The disc filtering element was difficult to manipulate. The only access was at the top of the case. 
- The clamp had a system with a bolt to open/close it, which made its use complicated as tools were required.

- The metal base only had an aligned water inlet and outlet.

The Classic filters range was based on a modular system that enabled a wide range of flows and configurations using a minimum number of components. The main filter components were as follows (Figure 2):

- $\quad$ The case, with the following elements:

$\bigcirc \quad$ The lid with two sizes.

- The base with three outlets housing to be used in different arrangements $\left(90^{\circ}\right.$ and $\left.180^{\circ}\right)$. These outlets housing had two sizes (2" and $\left.3^{\prime \prime}\right)$ and three connection types (BSP thread, NPT thread, and grooved connection).

- The stainless-steel clamp to be used without tools.

- The base cap according to the type of connection.

- The disc filtering element is held inside the case.

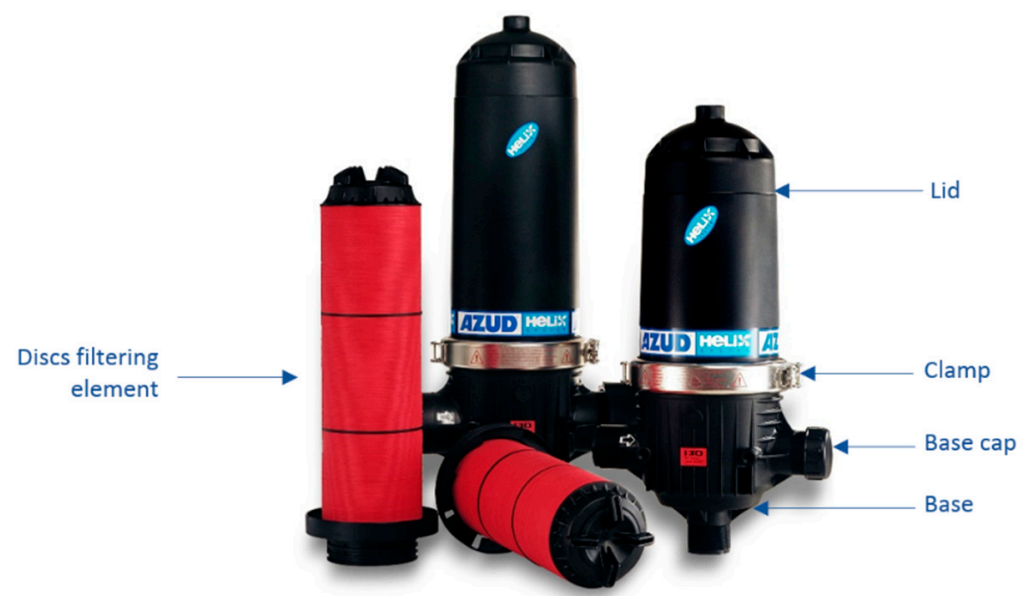

Figure 2. The Classic 2" and 3" filters range.

The technical characteristics of the filters were defined by the flow and maximum pressure per filter that they could withstand. The flows are sized for all the filters depending on whether the disc filtering element is manual or automatic, which also affects the quality of the water to be used for this sizing. The maximum recommended pressure for all the models is $10 \mathrm{~kg} / \mathrm{cm}^{3}$.

The material used to manufacture these components is fibreglass-reinforced polyamide 6 , with suitable additives to work outdoors for an approximately 10-year period. Short fibreglass-reinforced polyamide is hygroscopic and has a water absorption capacity to the saturation point of around 4-8\% depending on the quantity of reinforcement included. The thermal-mechanical performance of reinforced PA very much depends on moisture content.

All polyamides reversibly absorb water. The degree of water absorption depends on environmental relative humidity and on the degree of crystallinity. Moisture absorption implies increased volume; that is, a sizing alteration. This increase must be taken into account when calculating injection mould sizes and must be subtracted from the moulding contraction. The moisture content of polyamides must not exceed $0.3 \%$, so they must be dried before injecting. Water, which must be eliminated before moulding, must be replenished in a certain proportion after a part has been moulded because this certain proportion of the balance acts as a polyamide plasticiser. It can be stated that it is chemically combined with the polyamide and, if absent, the material would be too hard and would break.

The Classic filters range was available on the market for 10 years and was sold in some 35 countries all over the world. During all this time, exact or similar copies of the 
filter started appearing in several countries (Figure 3). In 2007, the company decided to adopt a new commercial strategy for this product by investing in the redesign of the filter to distinguish it from those of its competitors and all the copies that had appeared.

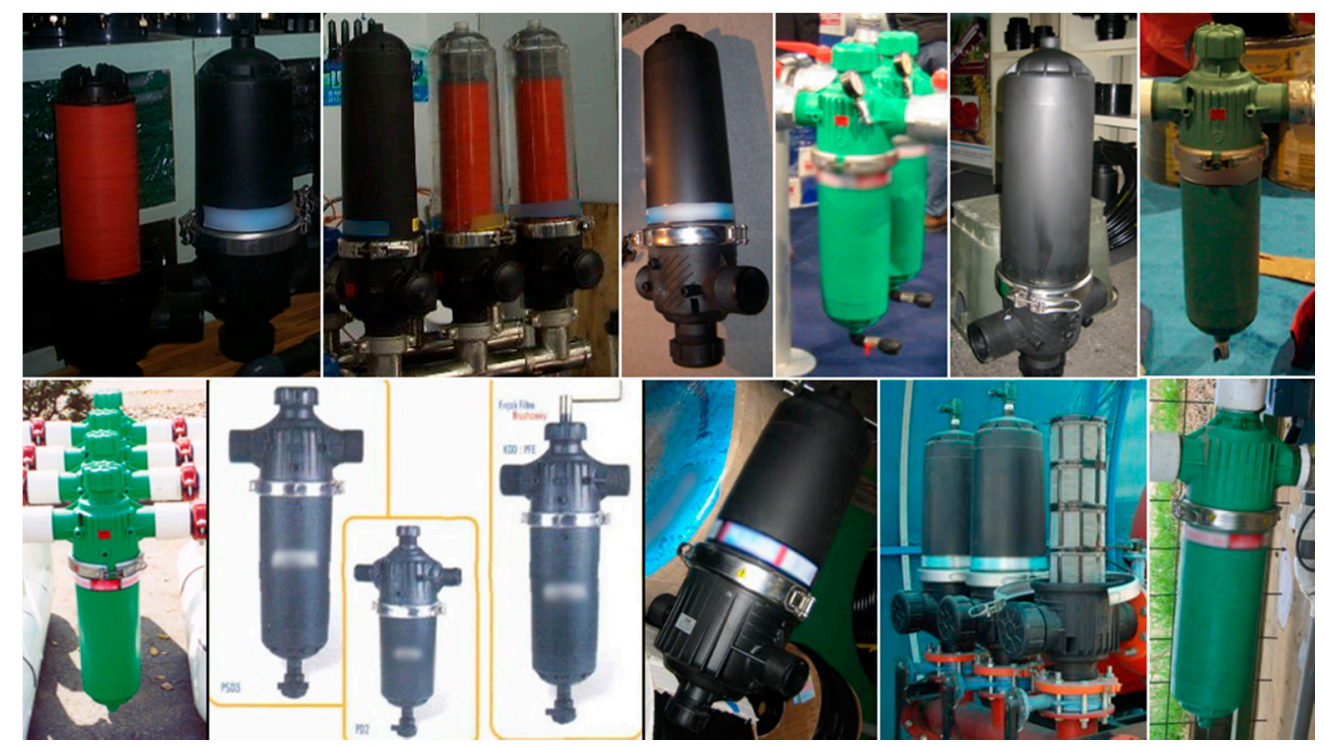

Figure 3. Examples of competitors' filters with a copy or very similar design to the Classic filter design.

\section{Materials and Methods}

Taking into account the literature in the field of product design, it is deduced the importance of specifying a series of steps to plan the development of a new product, in addition to defining the degree of novelty required for the new design [47]. Designing does not mean rapidly locating ideas, as this statement shows: "designing involves thinking before acting, and analysing, planning and performing to meet users' requirements" [48]. The followed design process (Figure 4) would be defined by several stages as suggested by some authors $[49,50]$ specifying different tasks focused on three important aspects: marketing, design, and manufacturing.

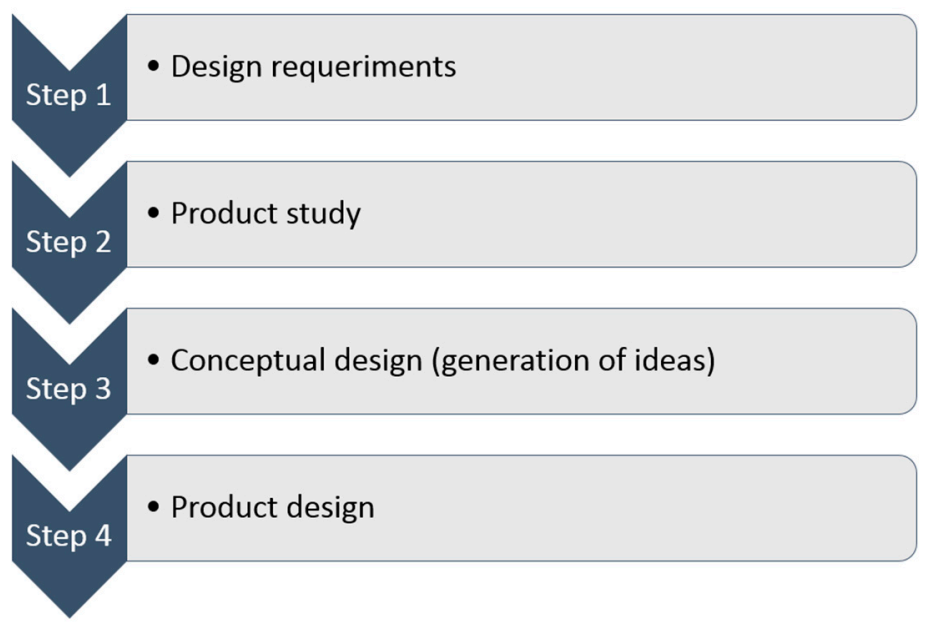

Figure 4. Diagram showing the design process.

Step 1. Design requirements: The following initial requirements of the project were defined among the managers and engineers of the company, evaluating technical and economic aspects such as the modularity of the different components, the existing injection moulds, the sale price of the product in the market, etc.: 
DR1. To obtain a filter design representative of the company so that customers can easily identify it.

DR2. To redesign only the outer area of the lid and the filter base by maintaining the same inner geometry.

DR3. To maintain the modular system of all the components to offer combinations of the same existing product.

DR4. To preserve the product's functional characteristics.

DR5. To control the weight and size of the lid and filter base to avoid increasing the cost of materials and production.

Step 2. Product study: In the previous section, the initial requirements specified by the company that defines the degree of novelty of the new product as an adaptive design have been described, that is, technical and operational aspects remain unchanged, and the aesthetic design adapts to the new fixed requirements or limitations [47]. In relation to the initial requirements, more specific requirements were determined:

DR1.1. New exterior geometry with a novel design.

DR2.1. The internal part of the body and the cover should have the same geometry (Figure 5a,b).

DR3.1. The assembly area of the body and the cover should keep the same shape (Figure 5c).

DR3.2. The input and output connections of the body should be the same to preserve connectivity with the other elements (Figure $5 \mathrm{~d}$ ).

DR4.1. The new case should withstand the maximum recommended pressure of $10 \mathrm{~kg} / \mathrm{cm}^{3}$.

DR5.1. Maintain the critical dimensions of the pieces.

DR5.2. Review the weights of the pieces of the new design comparing them with the previous model.

a)

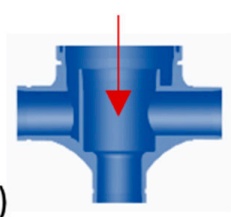

b)

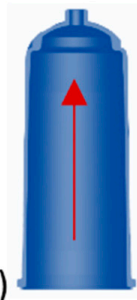

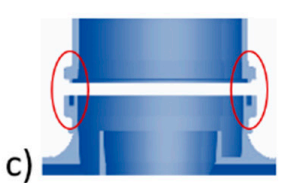

d)

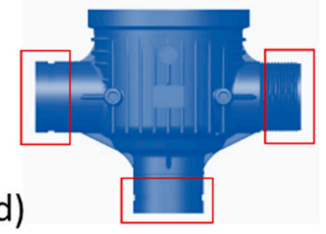

Figure 5. Functional aspects of the Filter: (a) The internal part of the body, (b) The internal part of the cover, (c) The assembly area of the body and the cover; and (d) The input and output connections of the body

Step 3. Conceptual design: When a designer is faced with the challenge of such an ambitious design, many questions and certain doubts arise as to his/her creative capacity. In 1950, North American psychologist Joy Paul Guilford gave his conference "Creativity" at the American Psychological Association to express that creativity involves avoiding what is obvious, certain, and predictable, and something novel is produced instead [51]. A wide variety of definitions can be found, including one of creativity as the capacity to produce something new $[52,53]$ as if it were a process of discovery, rediscovering or reorganising already existing knowledge [54], or transforming available information to create new ideas [55].

During the creative process, designers usually recur to several sources of inspiration to seek analogies from different domains and with the aim of obtaining inspiration. In this sense, two relevant aspects widely studied in this field are "fixation" and "inspiration", showing some studies how the use of examples facilitates the generation of novel and high-quality ideas [56-59].

In this project, elements that could serve as a source of inspiration were searched in nature. According to biomimetics expert Janine Benyus, biomimicry is divided into three levels (Figure 6): (i) a first reductive or superficial level, which consists of an imitation of 
the natural shape; (ii) a second level, which consists of the imitation of a natural process, a little deeper than the previous one and which is more sustainable (natural processes do not damage nature); (iii) a third level, which imitates natural ecosystems and is classified as deep or integral biomimicry. In this sense, a more superficial imitation was resorted to, based on the shapes and movements of some elements of nature [38].

Shallow/Reductive Biomimicry

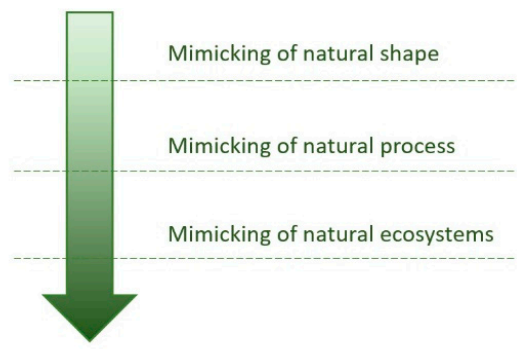

Deep/Holistic Biomimicry

Figure 6. Levels of biomimetics.

On the other hand, the method used to generate ideas was brainstorming, making a large number of sketches during the creative process. After several selection processes, the number of sketches was reduced. One of them (Figure 7a) was valued with greater interest by the work team because it suggested concepts with the product itself, raising the following question: Why not shift the water effect that takes place inside the filter to the outer case aesthetics?

The helix, or clogging-retardant device, has a helicoidal effect on water inside the filter so that any particles in suspension do not stick so quickly to the filtering discs (Figure 8a). This helicoidal effect on the water was the key part of this new design (Figure 8b). The next phase consisted of transferring this idea to the product concept (Figure $7 \mathrm{~b}$ ).

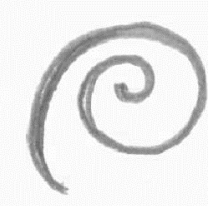

a)

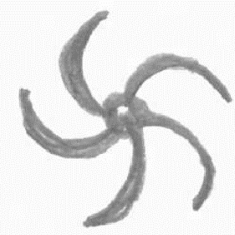

b)
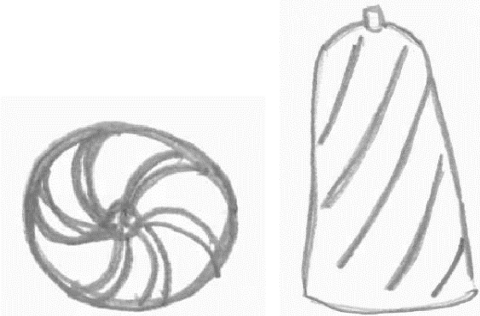

Figure 7. (a) Preliminary sketches, (b) Conceptual sketches of the lid.
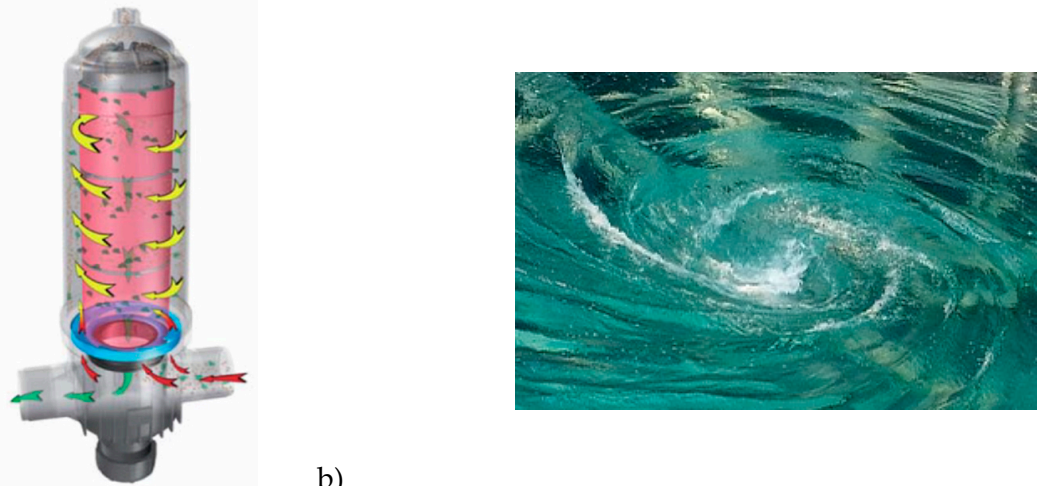

b)

Figure 8. (a) Representation of the helix effect on the water filtering process, (b) Swirling water (Source: www.pixabay.com, Accessed on 23 June 2020). 
Step 4. Product design: The Pro/Engineer computer-aided software (PTC Inc, Boston, MA, USA) was used to model the new designs. The main aspects taken into account during the filter design process were as follows:

- $\quad$ The upper lid part was defined with the helicoidal shape concept (Table 1a).

- $\quad$ The outer lid part was continued with a fluid shape. In order to accomplish it, reliefs that enhanced the helicoidal effect of ridges were designed (Table 1b).

- $\quad$ The outer base was designed by following the same inspiration as the lid (Table 1c).

- The lateral ridges of the base outlets housing were transformed into a bas-relief shape (Table 1d).

Table 1. Comparing the design details between the Classic model and the new model.

(a)
Top view
of the lid
$\begin{gathered}\text { (b) } \\ \text { Of the lid }\end{gathered}$
(d)
Side view
of the base
Front view
of the base

The proposed designs were presented to a company's multidisciplinary team made up of engineers, managers, and salesmen to assess the possible acceptance of this new design in the market, also evaluating possible changes or suggestions according to the approach of each participant. From this point on, new design requirements were considered: 
DR6. Redefine the new position of the main label on the cover.

DR7. The company logo should be part of the piece itself, consolidating the brand in the market.

DR8. Add the slogan "The original" to the design of the piece to differentiate it from competitors.

\section{Results}

The final model of the new product was revised taking into account the requirements set during the design process, highlighting the following aspects:

- Visual appearance of the product (DR1.1): the new filter revolutionised the filters market by projecting a new image of a functional-technical product that apparently had nothing new to offer because it was already functionally complete. It shifted the inner water effect to outside the case, and introduced the water's upward movement to the outer structure from the bottom of the body. This new asymmetric approach, which represented innovation in the market, allowed the new filter to not only be differentiated from the many copies found on the market but to launch a design inspired by helicoidal movement on the market, which was closely associated with the company brand.

- $\quad$ Parts geometry (DR2.1, DR3.1, DR3.2, and DR5.1): the new design maintains the same critical dimensions, the same internal geometry, and the connections with the other components.

- $\quad$ Recommended maximum pressure (DR4.1.): The casing was validated with pressure tests, exceeding the maximum recommended pressure of $10 \mathrm{~kg} / \mathrm{cm}^{3}$.

- Parts weight (DR5.2): Considering one of the design requirements defined in the previous chapter, weights, and volumes of the 3D models were analyzed using the Pro/Engineer software. The values obtained from the new design were compared with the Classic model, showing that variations between both models were not significant and, thus, the proposed designs were validated (Table 2).

Table 2. Comparing weights and volumes between the Classic model base and the new one.

\begin{tabular}{ccccc}
\hline & \multicolumn{2}{c}{ Classic Model } & \multicolumn{2}{c}{ New Model } \\
& Weight $\mathbf{( k g )}$ & Volume $\left.\mathbf{( c m}^{3}\right)$ & Weight $\mathbf{( k g )}$ & Volume $\left.\mathbf{( c m}^{3}\right)$ \\
\hline Base 2" & 1.89 & 1.47 & 2.04 & 1.58 \\
Base 3" $^{\prime \prime}$ & 2.06 & 1.60 & 2.24 & 1.74 \\
Lid 2" & 1.72 & 1.34 & 1.77 & 1.37 \\
Lid 3" & 2.33 & 1.80 & 2.36 & 1.83 \\
\hline
\end{tabular}

- $\quad$ Labels (DR6): Another implicit aspect of this new design was the position in which the main label was to be placed. In the Classic model, it was horizontally placed under the lid, but a decision was made to take advantage of the relief strip owing to the newly designed outer geometry to place the label. In this way, another filter aspect was innovated: where the label was placed. With its new asymmetric position, it is possible to see the filtration equipment and know that it is made by the company even from a distance as the label can be distinguished from those of its competitors (Figure 9). 


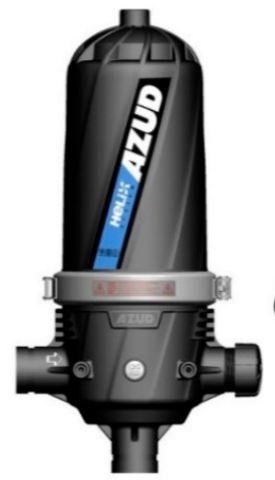

a)

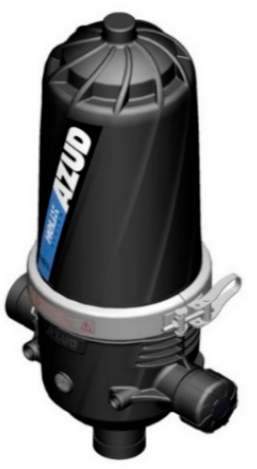

b)
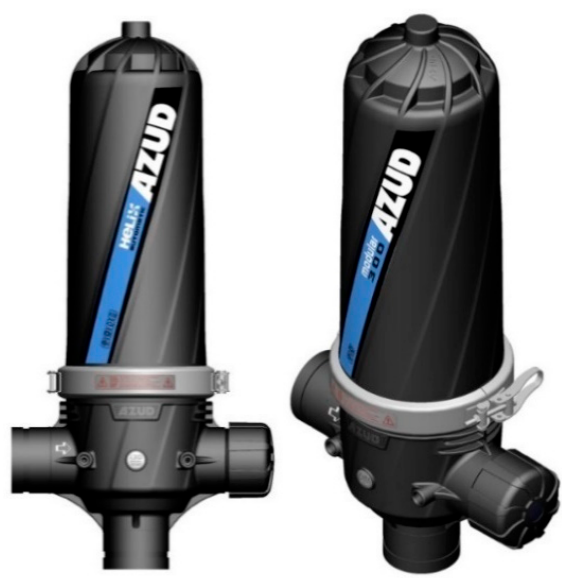

Figure 9. (a) The front and in-perspective views of the 3D filter 2" finished model, (b) the front and in-perspective views of the 3D filter 3" finished model.

- Brand and slogan (DR7 and DR8): Until this stage, labels had been used to identify the product and the different pieces of information that it had to bear. The engraving was introduced to establish a relation between the new product and the brand. This would allow the company logo to be clearly seen on both the base and lid and to also emphasise the origin of the design by introducing the slogan "The Original" to underline that the pioneering origin of this filter was the company name by engraving it on top of the lid (Figure 10).

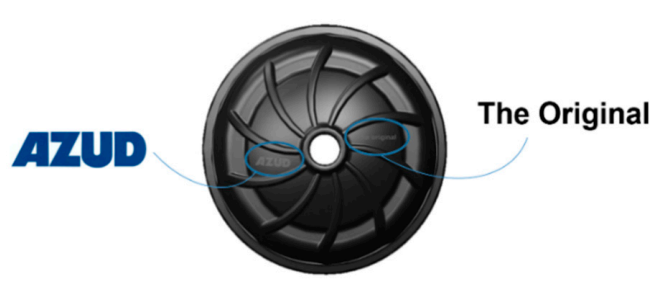

a) b)

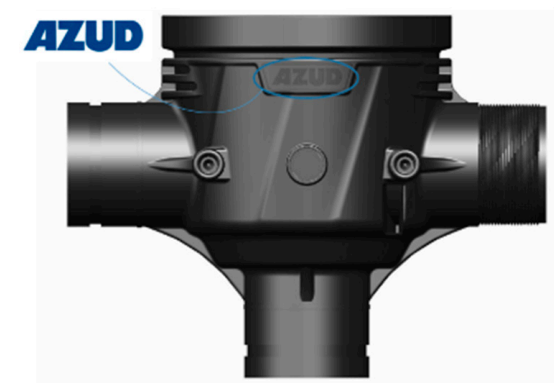

Figure 10. (a) Top view of the lid identifying the logo and slogan, (b) Front view of the base.

This project also involved designing a system of different coloured circular plastic plates attached to the base and base cap to identify the filters' degree of filtration and the company logo in such a way that they could be interchanged, resistant and durable. This system has its invention patent, called "Identifier of irrigation fitting and water filtration parts".

The time when an industrial designer may feel most satisfaction is when the finished end product is presented to them. Touching the physical parts of a design that they have been working on for so long, with which they have virtually lived with and have cared for each individual detail is a unique experience. The following figures allow us to view the completely finished filters, along with all the details of the new identifying labels and plates (Figure 11). 

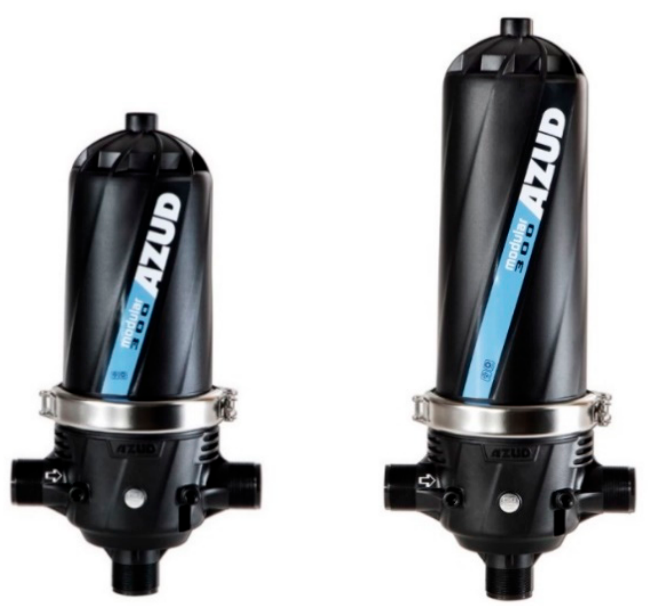

Figure 11. Front view of the 2" and 3" completely finished filters.

When a new product has been developed, the company must study which strategy has to be followed to determine the countries in which it will be protected. Thus, the new filter design was registered in the EU, China, and India, among others. Moreover, not only was the filter design registered in all its versions, but the various configurations of the equipment and of the variants that had been developed over the years were registered too.

\section{Discussion}

Different studies and reflections about the new product development process can be found. According to engineer L. Bruce Archer, "product design begins with a need" [59]. Most of the time it involves solving a problem, covering a need, and finding the most suitable solution in line with some initial requirements. Therefore, the question of whether a methodology is needed to develop a new product or if it is simply a matter of finding an idea may arise. Designer Bruno Munari indicates that undertaking a project with no method is not right, but it is necessary to conduct a previously documented study of all the product-related aspects before starting to design [60].

So, it is necessary to think of the use of a method as being important to put into practice a good idea or solution for a given problem under study. Psychology teacher Mihaly Csikszentmihalyi summarised the creative process in five phases to propose how to advance in the creative process in a simple and organised fashion: preparation, incubation, insight, evaluation, and elaboration [61,62]. Munari considered two end-points in this process, the problem (as the starting point) and the solution (as the goal) by introducing a series of intermediate steps between them to help solve the problem. "The problem cannot be solved on its own, but contains all the elements to solve it; we need to know them and use them in the solution project" [59]. In line with this, several methodologies can be found in the literature that can guide designers through the various design process phases [63], but they all share similar arguments. Hence, it can be deduced that a single method to develop the design process and to obtain the pursued solution does not have to exist. According to Simón [64], the design method is not set but is flexible and adaptable to the circumstances in the surroundings and those of the designers themselves. Mental, manual, intuitive, and rational factors intervene in this process, which might help create useful and beautiful shapes. Taking into account the specific literature on product design, the existing reference methodologies were evaluated for the definition of the different steps followed in the design process of this project $[47,49,50]$.

Concurrent design is a term that is especially relevant in this area because it does not take a designer as an isolated figure, but one who interconnects with the other departments involved in the company. A company's aim is to develop functional and appealing quality products in suitable launching times at a minimum cost. To fulfil all these objectives, it is necessary to converge in, or make simultaneous during the design phase, different technological data from these departments related to the product's life cycle [65]. 
The company's design did not only centre on product design, but also involved different organisational levels, where each played a relevant role in improving its image and its own identity. This can be applied in the company from three different perspectives [48]:

(a) Industrial/product design, where shape, building, usefulness, and semantic aspects, as well as other product characteristics that will come into contact with users, are established. To accomplish this design type, other aspects need to be included in the company's strategy, like understanding the experience acquired from use, technical knowledge, manufacturing processes, and the business strategy.

(b) Product communication, where the best conditions are created to identify and recognise the product by different communication supports (brand, web, catalogues, etc.). These supports must be coherent with one another, with the product, and with the image that the company wishes to portray.

(c) Corporate image design, where the company's image is presented to the public. This design type includes all internal/external communication actions performed in the company.

Thus, all those companies that are in control of the design of all the aspects that relate to it offer their own personality and set the pace of the market as opposed to their competitors, no matter what field they operate in [3]. In the beginning, the Classic filter case was designed by bearing in mind only functional aspects, which was because simple smooth lines were defined, with ridges and structures to provide reliable resistance. Aesthetic design was not relevant at the time because industrial registration was not considered possible, and this filter also was never thought to become the most copied filter in the world.

In this sense, the following question is raised: can a change in the product's appearance be considered an innovative activity? The Oslo Manual is a guideline for collecting, reporting, and using data on innovation, and comments as follows: "Innovating is using knowledge, and generating it if necessary, to create products, services or processes that are new to the company, or improve existing ones, thereby achieving success in the market" [66]. The design process of this product is a clear example of how to raise the importance of design at different levels, enabling obtaining innovation and technological recognition in the market, for which the involvement of the entire company is important. The creative process played an important role in this project, where several important aspects were considered, both individually and organizationally. As some studies reflect, creativity can be the result of individuals or teams, regardless of their functional areas and positions in the organizational hierarchy. If organizations select employees who have a natural inclination to be creative, and the organizational context is not supportive, the creative potential of the employees will not be realized [67]. In this case, the leadership of the company's managers was key in creating an environment that supported creativity and the implementation of novel ideas. As some studies indicate, the company's managers must consider the changing nature of competition during industry evolution while developing strategies that encompass the use of industrial design in new product development. Thus, being innovative with respect to design and design strategy can help to enhance competitiveness regardless of industry evolution [6].

Taking into account the above, it is worth asking whether it is appropriate to redesign the aesthetic appearance of this type of product, whose functionality is apparently more important to consumers. In practical terms, one might think not, but in such a globalized market, brand image is almost as important as the product itself. For this reason, the redesign of this product, so characteristic of the company and so copied by the competition, is a relevant example in the field of design and in the business sector focused on agronomy. A good design is capable of transmitting quality and confidence (key aspects for consumers in any sector) through its aesthetic appearance [68].

Regarding the new visual appearance forms implemented in the new product, different variants of these forms and their impact on users were not studied in depth. This aspect has been extensively studied in other works where the impact of multisensory stimulations 
on the evaluation and choice of products are already assessed [69], as well as the emotional response and purchasing behaviour of users [70]. The study of the influence of the tactile or visual signals generated by this design change has not been considered relevant to be implemented in this study, although it can be evaluated in future lines of research.

On the other hand, other important aspects that must be considered today in projects similar to the one proposed in this article are the Digitalization of the economy, Industry 4.0, and the Internet of Things. When this project was developed, they were not determining aspects, but at present, it is essential to consider them because they can improve both the planning and the manufacture of any product [71].

In this project, all the objectives proposed at the beginning were achieved, which were to innovate in the aesthetic appearance of an agronomic and industrial product to differentiate it from its competitors, although some limitations were also found during the research. The main limitations were located in the collection of statistical data on the evolution of this product in the market and the impact of its aesthetic redesign on its sales. For confidential reasons of the company itself, it has not been possible to collect this data and offer the results in this work. A future line of work may focus on collecting information on customers and users to assess their experience with this type of product and their relationship with the company.

\section{Conclusions}

In the agronomic field, those products that comply with a series of technical and functional characteristics stand out. However, there are also successful examples in which an innovative aesthetic value is added to the product, making it an outstanding reference in the market and among its competitors. For this reason, this paper describes the redesign process of a filter that stood out in the agronomic field for its aesthetic appearance. The background of the product and the strategy to be considered were analyzed due to the numerous copies available of the previous filter. The main objective was to distinguish it from other competitors' products and to offer a clear image of the company's brand.

The study shown in this article has considered the product journey of the filter case for 20 years, where two important phases can be compared: i) a first phase in which the Classic filter was designed bearing in mind only technical and functional aspects, ii) and a second phase in which the aesthetic and symbolic values were incorporated into the design of the new filter. In the first stage, the product became relevant in the market, but the competitors gradually copied the design, making it difficult to differentiate between them. In the second stage, the aesthetic concept of the product was redefined, using design requirements that guided the project, employing methodologies such as brainstorming, and applying a design based on analogies from nature. Its inspiration in the asymmetric shape of water with a helicoidal effect was the main driver of this ground-breaking design, which is a reference in the market and has allowed industrial design registration in various countries around the world.

Author Contributions: Conceptualization, D.P.-B. and D.G.F.-P.; methodology, D.P.-B. and D.G.F.-P.; formal analysis, F.J.F.C.; investigation, D.P.-B. and D.G.F.-P.; writing-original draft preparation, D.P.-B.; writing-review and editing, D.G.F.-P. and F.J.F.C.; visualization D.P.-B. and D.G.F.-P. All authors have read and agreed to the published version of the manuscript.

Funding: This research received no external funding.

Institutional Review Board Statement: Not applicable.

Informed Consent Statement: Not applicable.

Data Availability Statement: Data is contained within the article.

Acknowledgments: We thank Sistema AZUD S.A. company for all the provided data and information that enabled to write this manuscript. Special thanks go to Manuel García, Marta García, Pablo Jumilla, María Teresa Munuera, José Miguel López and Yusimí Rodríguez for their contributions and suggestions. 
Conflicts of Interest: The authors declare no conflict of interest.

\section{References}

1. Gay, A.; Samar, L. Industrial Design in History; Ediciones Tec: Córdoba, Argentina, 2004. (In Spanish)

2. $\quad$ Ulrich, K.T. Design Is Everything? J. Prod. Innov. Manag. 2011, 28, 394-398. [CrossRef]

3. Lecuona, M. Handbook on Design Management for Companies Opening New Markets; Centro de Diseño: Barcelona, Spain, 2007. (In Spanish)

4. Norman, D.A. Emotional Design. Why We Love (or Hate) Everyday Things; Basic Books: New York, NY, USA, 2004.

5. Ulrich, K.T. Design: Creation of Artifacts in Society; University of Pennsylvania: Philadelphia, PA, USA, $2011 ;$ p. 184.

6. Gemser, G.; Leenders, M.A.A.M. How integrating industrial design in the product development process impacts on company performance. J. Prod. Innov. Manag. 2001, 18, 28-38. [CrossRef]

7. Micheli, P.; Perks, H.; Beverland, M.B. Elevating Design in the Organization. J. Prod. Innov. Manag. 2018, 35, 629-651. [CrossRef]

8. Bloch, P.H. Seeking the ideal form: Product design and consumer response. J. Mark. 1995, 59, 16-29. [CrossRef]

9. Candi, M. Benefits of aesthetic design as an element of new service development. J. Prod. Innov. Manag. 2010, 27, 1047-1064. [CrossRef]

10. Coates, D. Watches Tell More than Time: Product Design, Information and the Quest for Elegance; McGraw-Hill: New York, NY, USA, 2003; p. 281.

11. Crilly, N.; Moultrie, J.; Clarkson, P.J. Shaping things: Intended consumer response and the other determinants of product form. Des. Stud. 2009, 30, 224-254. [CrossRef]

12. Jagtap, S. Attributes and Emotions in Product Form Design: A Survey of Professional Industrial Designers. In Research into Design for Communities; Springer: Singapore, 2017; Volume 2, pp. 705-714.

13. Townsend, J.D.; Kang, W.; Montoya, M.M.; Calantone, R.J. Brand-specific design effects: Form and function. J. Prod. Innov. Manag. 2013, 30, 994-1008. [CrossRef]

14. Veryzer, R.W. Key factors affecting customer evaluation of discontinuous new products. J. Prod. Innov. Manag. 1998, 15, 136-150. [CrossRef]

15. Chakrabarti, A.; Morgenstern, S.; Knaab, H. Identification and application of requirements and their impact on the design process: A protocol study. Res. Eng. Des. 2004, 15, 22-39. [CrossRef]

16. Eisentraut, R.; Badke-Schaub, P. Creativity: A Personality Trait or an Illusion. In Proceedings of the International Workshop Engineering Design and Creativity, Pilsen, Czech Republic, 16-18 November 1995; State Scientific Library: Pilsen, Czech Republic, 1995.

17. Sarkar, P.; Chakrabarti, A. Assessing design creativity. Des. Stud. 2011, 32, 348-383. [CrossRef]

18. Eckert, C.; Stacey, M. Sources of inspiration: A language of design. Des. Stud. 2000, 21, 523-538. [CrossRef]

19. Goldschmidt, G.; Sever, A.L. Inspiring design ideas with texts. Des. Stud. 2011, 32, 139-155. [CrossRef]

20. Herring, S.R.; Chang, C.C.; Krantzler, J.; Bailey, B.P. In Getting inspired!: Understanding How and Why Examples Are Used in Creative Design Practice. In Proceedings of the SIGCHI Conference on Human Factors in Computing Systems, Boston, MA, USA, 6 April 2009; pp. 87-96.

21. Im, S.; Workman, J.P., Jr. Market orientation, creativity, and new product performance in high-technology firms. J. Mark. 2004, 68, 114-132. [CrossRef]

22. Christiaans, H.H. Creativity as a design criterion. Commun. Res. J. 2002, 14, 41-54. [CrossRef]

23. Cropley, D.H.; Kaufman, J.C.; Cropley, A.J. Measuring creativity for innovation management. J. Technol. Manag. Innov. 2011, 6, 13-30. [CrossRef]

24. Moreno-Moya, M.; Munuera-Alemán, J.L. Is creativity important in new product development? Universia Bus. Rev. 2014, 4, 72-87.

25. Cox, G.; Dayan, Z. Cox Review of Creativity in Business: Building on the UK's Strengths; TSO: Norwich, UK, 2005 ; p. 47.

26. Howard, T.J.; Culley, S.J.; Dekoninck, E. Describing the creative design process by the integration of engineering design and cognitive psychology literature. Des. Stud. 2008, 29, 160-180. [CrossRef]

27. Gonçalves, M.; Cardoso, C.; Badke-Schaub, P. What inspires designers? Preferences on inspirational approaches during idea generation. Des. Stud. 2014, 35, 29-53. [CrossRef]

28. Jagtap, S. Inspiration in Product Form Design: A Survey of Professional Industrial Designers. In Research into Design for Communities; Springer: Singapore, 2017; Volume 2, pp. 715-725.

29. Parras-Burgos, D.; Fernández-Pacheco, D.G.; Cavas-Martínez, F.; Martínez, J.N.; Cañavate, F.J. An agent-based approach for the application of nature's forms to product conceptual design. PLoS ONE 2018, e0208930. [CrossRef]

30. Wang, K.; Nickerson, J.V. A literature review on individual creativity support systems. Comput. Hum. Behav. 2017, 74, 139-151. [CrossRef]

31. Wu, T.Y.; Chen, H.K. Products with Biomimetic Shapes Convey Emotions More Effectively. In Proceedings of the 4th International Conference on Design, User Experience and Usability, Los Angeles, CA, USA, 2-7 August 2015; pp. 559-566.

32. Bar-Cohen, Y. In Biomimetics: Mimicking and Inspired-by Biology. In Proceedings of the SPIE Smart Structures Conference, San Diego, CA, USA, 10 March 2005; pp. 1-8.

33. Bar-Cohen, Y. Biomimetics-using nature to inspire human innovation. Bioinspiration Biomim. 2006, 1, 1-12. [CrossRef]

34. Lepora, N.F.; Verschure, P.; Prescott, T.J. The state of the art in biomimetics. Bioinspiration Biomim. 2013, 8, 013001. [CrossRef] 
35. Giardili, G.A. Industrializing Nature or Naturalizing Design; Universidad de Belgrano: Buenos Aires, Argentina, 2012. (In Spanish)

36. López, A.D. Nature, Mother of Design. Source of Inspiration for the Creation of Objects; Universidad de Palermo: Buenos Aires, Argentina, 2010. (In Spanish)

37. Urbina, I. Bionics. Rescue of Natural Systems. Available online: http://www.objetual.com/di/articulos/bionica1.htm (accessed on 27 November 2017). (In Spanish).

38. Volstad, N.L.; Boks, C. In Biomimicry-A Useful Tool for the Industrial Designer? In Proceedings of the NordDesign 2008 Conference, Tallinn, Estonia, 21-23 August 2008.

39. Kalogerakis, K.; Lüthje, C.; Herstatt, C. Developing innovations based on analogies: Experience from design and engineering consultants. J. Prod. Innov. Manag. 2010, 27, 418-436. [CrossRef]

40. Keshwani, S.; Chakrabarti, A. Towards Automatic Classification of Description of Analogies into SAPPhIRE Constructs. In Research into Design for Communities; Springer: Singapore, 2017; Volume 2, pp. 643-655.

41. Vattam, S.S.; Helms, M.E.; Goel, A.K. In Nature of Creative Analogies in Biologically Inspired Innovative Design. In Proceedings of the Seventh ACM Conference on Creativity and Cognition, Berkeley, CA, USA, 27-30 October 2009; ACM: New York, NY, USA; pp. 255-264.

42. Daugherty, J.; Mentzer, N. Analogical reasoning in the engineering design process and technology education applications. J. Technol. Educ. 2008, 19, 7-21. Available online: https:/ /digitalcommons.usu.edu/cgi/viewcontent.cgi?article=1009\&context= ncete_publications (accessed on 18 June 2020).

43. Lizoňová, D.; Tončíková, Z. Exploring the application of nature-inspired geometric principles when designing furniture and interior equipment. Acta Fac. Xylologiae Zvolen Publica Slovaca 2019, 61, 131-145. [CrossRef]

44. Roe, E.T.; Bies, A.J.; Montgomery, R.D.; Watterson, W.J.; Parris, B.; Boydston, C.R.; Sereno, M.E.; Taylor, R.P. Fractal solar panels: Optimizing aesthetic and electrical performances. PLoS ONE 2020, 15, e0229945. [CrossRef] [PubMed]

45. Costa, J. Corporate Image in the 21st Century; Editorial La Crujía: Buenos Aires, Argentina, 2003. (In Spanish)

46. Güell, J.M.F. Scenario Design in the Business Environment; Ediciones Pirámide: Madrid, Spain, 2004. (In Spanish)

47. Pahl, G.; Beitz, W. Engineering Design: A Systematic Approach; Springer Science \& Business Media: London, UK, 2013.

48. INTI. Design process. Phases for Product Development; Instituto Nacional de Tecnología Industrial: Buenos Aires, Argentina, 2009; Volume 141. (In Spanish)

49. Simmons, C.H.; Maguire, D.E. Manual of Engineering Drawing: Technical Product Specification and Documentation to British and International Standards; Butterworth-Heinemann: Burlington, MA, USA, 2012.

50. Ulrich, K.; Eppinger, S. Product Design and Development; McGraw-Hill Irwin: New York, NY, USA, 2012.

51. Vass, V. The Transition of Creativity in Education. The Age of Creativity: Crisis or Golden Age? J. Res. Educ. 2015, 2, 1-5.

52. Cuevas Romero, S. Creativity in education, its develpment from a pedagogical perspective. J. Sport Health Res. 2013, 5, 221-228.

53. Sikora, J. Handbook of Creative Methods; Kapelusz: Buenos Aires, Argentina, 1979. (In Spanish)

54. Logan, L.M.; Logan, V.G.; García, A.R. Strategies for Creative Teaching; Oikos-tau Ediciones: Vilasar de Mar, Barcelona, Spain, 1980. (In Spanish)

55. De la Torre, S. Creativity and Culture. In Creatividad polivalente. Actas y Congresos; Universidad Nacional de Educación a Distancia: Madrid, Spain, 1998; pp. 125-127. (In Spanish)

56. Fiorineschi, L. Abstraction framework to support students in learning creative conceptual design. J. Eng. Des. Technol. 2018. [CrossRef]

57. Howard, T.J.; Culley, S.; Dekoninck, E.A. Reuse of ideas and concepts for creative stimuli in engineering design. J. Eng. Des. 2010, 22, 565-581. [CrossRef]

58. Jansson, D.G.; Smith, S.M. Design fixation. Des. Stud. 1991, 12, 3-11. [CrossRef]

59. Sio, U.N.; Kotovsky, K.; Cagan, J. Fixation or inspiration? A meta-analytic review of the role of examples on design processes. Des. Stud. 2015, 39, 70-99. [CrossRef]

60. Munari, B.; Rodriguez, C.A. How are Objects Born? Notes for a Design Methodology; Ed. Gustavo Gili: Barcelona, Spain, 1983. (In Spanish)

61. Csikszentmihalyi, M. Creativity: The Flow and Psychology of Discovery and Invention; Paidós Barcelona: Barcelona, Spain, 1998. (In Spanish)

62. Esparza Ramírez, J.L. Factors Influencing Design Product Innovation; Universidad Autónoma de Nuevo León: Nuevo Leon, Mexico, 2012. (In Spanish)

63. Adams, K.M. Design methodologies. In Nonfunctional Requirements in Systems Analysis and Design; Springer: Cham, Switzerland, 2015; pp. 15-43.

64. Simón Sol, G. Why We Need Methods to Design; The Design Framework; Designio: Mexico City, Mexico, 2009. (In Spanish)

65. Espinosa, M.M.; Domínguez, M. Concurrent Engineering; Asociación de Ingeniería y Diseño Asistido: Madrid, Spain, 2007. (In Spanish)

66. OECD. Proposed guidelines for collecting and interpreting technological innovation data. In The Measurement of Scientific and Technological Activities; Statistical Office of the European Communities; European Commission; Eurostat; European Union: Brussels, Belgium, 2005.

67. Zhou, J.; Hoever, I.J. Research on workplace creativity: A review and redirection. Annu. Rev. Organ. Psychol. Organ. Behav. 2014, 1, 333-359. [CrossRef] 
68. Crilly, N.; Moultrie, J.; Clarkson, P.J. Seeing things: Consumer response to the visual domain in product design. Des. Stud. 2004, 25, 547-577. [CrossRef]

69. Balaji, M.; Raghavan, S.; Jha, S. Role of tactile and visual inputs in product evaluation: A multisensory perspective. Asia Pac. J. Mark. Logist. 2011. [CrossRef]

70. Pramudya, R.C.; Seo, H.-S. Hand-feel touch cues and their influences on consumer perception and behavior with respect to food products: A review. Foods 2019, 8, 259. [CrossRef] [PubMed]

71. Ahmed, M.B.; Majeed, F.; Sanin, C.; Szczerbicki, E. Experience-Based Product Inspection Planning for Industry 4.0. Cybern. Syst. 2021. [CrossRef] 